\title{
EKSPLORASI PENERAPAN PENDEKATAN SCIENTIFIC DITINJAU DARI PENGETAHUAN PEDAGOGIK GURU
}

\author{
Muahammad Ali P1, Suryadi Ishak ${ }^{2}$ \\ Prodi Pendidikan Matematika Universitas Al Asyariah Mandar \\ e-mail: muahammad.ali.palaha@gmail.com
}

\begin{abstract}
The main instrument in this study is the researcher himself and his supporting instruments are the teacher's pedagogical knowledge test, learning observation sheet, and interview. The subjects of the study were mathematics teachers at SMP Negeri 1 Polewali, SMP Negeri 2 Polewali, and SMP Negeri 3 Polewali, which were then chosen by two people from each school. The results obtained from this study are the first based on the results of pedagogical tests given to research subjects, namely there are 2 subjects that fall into the category of high pedagogical knowledge and there are 4 subjects that fall into the category of low pedagogic knowledge and based on interviews the results show subjects that fall into the knowledge category High pedagogic generally understands how the application of scientific approaches in mathematics learning because they have frequently participated in training related to the scientific approach, whereas subjects with low pedagogic knowledge category only one subject understands the application of the scientific approach because they are active in the training carried out by the relevant offices. and for the other 3 subjects they did not really understand the scientific approach because they had only participated in the training once. Based on observations, it shows that (1) subjects who have a high pedagogical knowledge category are generally good in applying learning steps because it is clear in directing students in the learning process so that some students are able to follow them well. (2) subjects who have a low pedagogical knowledge category are generally not good at implementing learning steps because they are not clear in directing students in the learning process so that students cannot follow them well.
\end{abstract}

Keywords: pedagogic, scientific approach, mathematics

\section{PENDAHULUAN}

Pendekatan scientific yang merupakan kebijakan pemerintah dalam kurikulum baru yaitu kurikulum 2013 diharapkan menjadi sebuah solusi yang dapat diterapkan guru dalam pembelajaran khususnya dalam pembelajaran matematika. Walau kurikulum baru yang dicanangkan oleh pemerintah tersebut masih dirasakan sebagai sesuatu yang sulit. 
Permasalahan-permasalahan tersebut juga dikeluhkan oleh guru khususnya guru matematika untuk penerapan pendekatan scientific dalam pembelajaran matematika di SMP. Permasalahan yang menjadi kendala guru dalam penerapan pendekatan scientific tersebut disebabkan oleh beberapa faktor diantaranya ketidakmampuan mengembangkan indikator-indikator dalam pembelajaran, memerlukan kreatifitas dan wawasan yang luas dalam mengarahkan siswa untuk memahami komponen-komponen scientific, masih kaku dalam penerapan materi yang diajarkan dengan pendekatan scientific termasuk pada materi Logika, kebanyakan guru belum bisa meninggalkan metode-metode mengajar yang masih konvensional, siswa masih dipengaruhi oleh karakter lingkungan belajarnya serta tingkat kecerdasan siswa juga berbeda-beda.

Dalam penerapan materi oleh guru salah satunya adalah logika matematika masih sangat sulit padahal karakteristik materinya dianggap beberapa orang sangat sesuai dengan konsep penerapan scirntific yang memuat komponenkomponen scientific itu sendiri, oleh karena itu materi logika dipilih selain karena memiliki karakteristik yang tepat dalam pembelajaran dengan penerapan pendekatan scientific juga materi ini masih dianggap sulit oleh siswa.

\section{METODE PENELITIAN}

\section{Jenis Penelitian}

Penelitian ini merupakan penelitian eksploratif yang bersifat kualitatif yang bertujuan untuk menggali informasi tentang pelaksanaan pendekatan scientific dalam pembelajaran matematika yang dilaksanakan guru ditinjau dari pengetahuan pedagogik. Pelaksanaan pendekatan scientific yang dilaksanakan dalam pembelajaran matematika dapat dilihat pada proses pembalajaran yang dilakukan guru di dalam kelas yang tercermin dari penerapan komponenkomponen pendekatan scientific yaitu mangamati, menanya, menalar, mencoba, dan membentuk jejaring pada materi-materi yang diajarkan

\section{Subjek Penelitian}

Semua Guru matematika SMP negeri yang ada di kecamatan Polewali MAndar yang diwakili oleh 3 sekolah dengan pertimbangan kualitas dan sarana lebih memadai dari SMP Negeri yang lain.

\section{Fokus Penelitian}

Fokus penelitian yang diterapkan berfungsi mengarahkan peneliti sehingga dapat mencurahkan perhatian secara jelas apa yang semestinya diteliti agar pertanyaan penelitian dapat dijawab dengan sebaik-baiknya. Untuk menjawab pertanyaan penelitian dengan baik maka yang menjadi fokus penelitian ini adalah: pelaksanaan pendekatan scientific dalam pembelajaran matematika oleh guru dengan indikator-indikator sebagai berikut. 
Menyajikan materi pembelajaran dengan menggunakan pendekatan scientific. Mengelola kelas dengan baik melalui penerapan model pembelajaran dengan pendekatan scientific.

\section{Instrumen Penelitian}

Instrumen penelitian adalah peneliti sendiri. Dalam hal ini peneliti merupakan perencana, pelaksana pengumpul data, penganalisis, penafsiran data, dan menjadi pelapor hasil penelitian. Peneliti sebagai instrumen akan mempermudah menggali informasi yang menarik meliputi informasi lain dari yang lain (temuan-temuan yang menarik), yang tidak direncanakan sebelumnya, yang tidak terduga terlebih dahulu atau yang tidak lazim terjadi. Pada penelitian ini juga digunakan instrumen pendukung lainnya yaitu: (1) tes pengetahuan pedagogik guru (2) lembar observasi yang bertujuan untuk menilai kinerja guru dalam pelaksanaan pendekatan scientific dalam proses pembelajaran yang berlangsung di dalam kelas, dan (3) Pedoman wawancara dengan tujuan untuk melengkapi data-data hasil observasi.

\section{Teknik Pengumpulan Data dan Validasi Data}

Proses Pengumpulan data dalam penelitian ini dilakukan melalui observasi dan wawancara namun terlebih dahulu diberikan tes untuk mengukur pengetahuan pedagogik calon subjek. Tes ini dilakukan untuk mengetahui tingkat pengetahuan pedagogik calon subjek yaitu pengetahuan pedagogik tinggi, pengetahuan pedagogik sedang, dan pengetahuan pedagogik rendah

\section{Teknik Analisis Data}

Miles dan Huberman (dalam Sugiyono, 2006) mengemukakan bahwa aktivitas dalam analisis data kualitatif dilakukan secara interaktif dan berlangsung secara terus menerus sampai tuntas, sehingga datanya sudah jenuh. Proses analisis data dimulai sejak pengumpulan data sampai pada saat peneliti menyelesaikan tugas di lapangan. Ketika peneliti mulai mengumpulkan data, analisis dilakukan terhadap pertanyaan yang diajukan berdasarkan respon subjek. Misalkan, jika respon subjek terhadap pertanyaan yang diajukan tidak sesuai dengan tujuan penelitian dan menurut analisis peneliti, respon yang diberikan tidak menarik untuk diungkapkan, maka diajukan pertanyaan dengan kalimat yang berbeda, namun tetap dalam inti permasalahan. Tetapi, jika respon subjek menarik untuk diungkap, meskipun tidak sesuai dengan tujuan penelitian, maka peneliti mengajukan pertanyaan yang sifatnya menggali. Data yang telah terkumpul dan masih dalam bentuk instrument penilaian observasi dan rekaman, khusus untuk hasil wawancara maka selanjutnya ditransformasi ke dalam bentuk transkrip wawancara. 


\section{HASIL DAN PEMBAHASAN}

Gambaran pelaksanaan pendekatan scientific guru matematika yang memilik pengetahuan pedagogik tinggi dan pengetahuan pedagogic rendah, pada tiga Sekolah (SMP) di Kecamatan Polewali Mandar, dengan melihat hasil tes pedagogic, hasil wawancara mengenai pemahaman tentang pendekatan scientific dan implementasinya dalam pembelajaran, serta mengobservasi indikatorindikator yang dieksplorasi berdasarkan pedoman wawancara pada saat pembelajaran.

Hasil tes pengetahuan pedagogic guru dikategorikan menjadi dua yaitu pengetahuan pedagogik tinggi dan pengetahuan pedagogik rendah, berdasarkan hasil tes ada 3 subjek yang masuk pada kategori tinggi dan ada 3 subjek yang masuk pada kategori rendah. Selanjutnya ke enam subjek tersebut akan dilihat tingkat pemahamannya dalam pelaksanaan pendekatan scientific dalam pembelajaran matematika melalui pedoman wawancara yang selanjutny dilakukan pengamatan untuk melihat indicator-indikator yang dieksplorasi berdasarkan pedoman wawancara.

\section{Hasil Tes Pengetahuan Pedagogik}

Pengetahuan pedagogik guru yang berkenaan dengan kemampuan memahami karakteristik peserta didik, kemampuan merencanakan dan melaksanakan pembelajaran, kemampuan komunikasi dengan peserta didik, kemampuan melaksanakan evaluasi dan penilaian proses hasil belajar, serta pengembangan peserta didik untuk mengaktualisasikan berbagai potensi yang dimilikinya seperti yang telah dijelaskan sebelumnya dapat digambaran sebagai berikut:

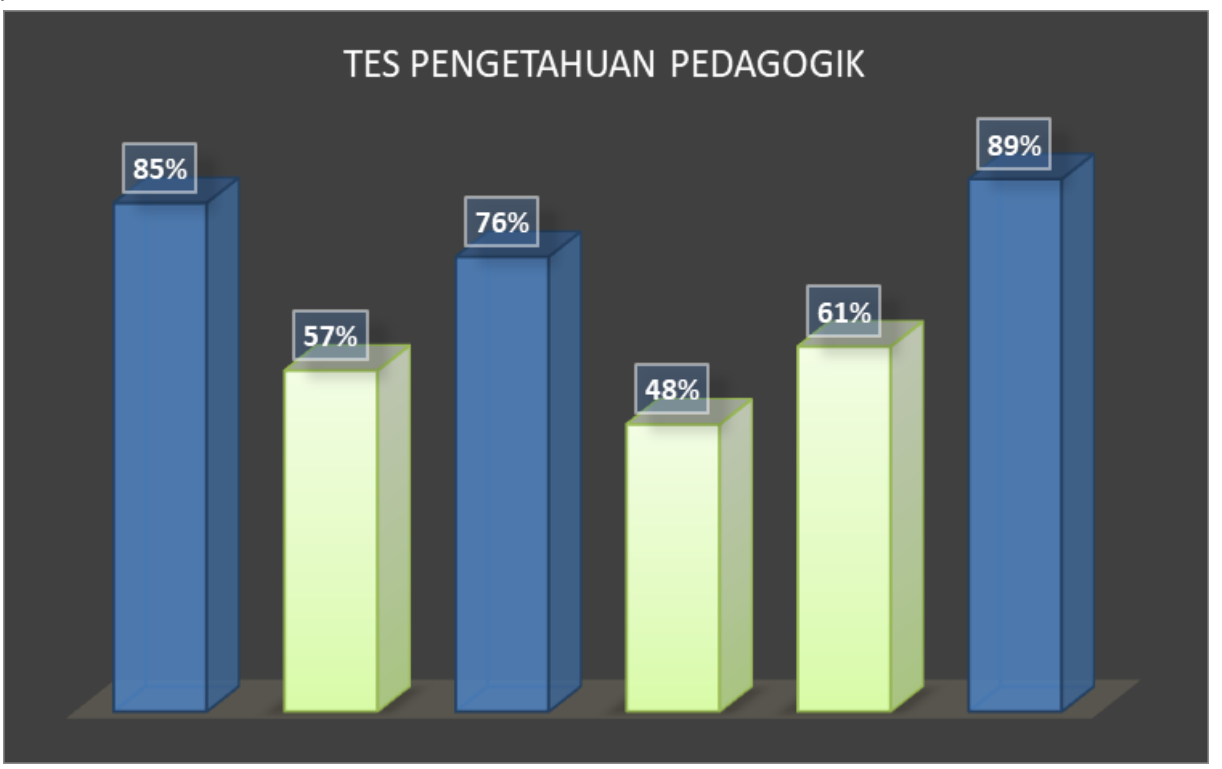


Hasil perolehan tes pengetahuan pedagogik guru Matematika SMP Negeri di kecamatan Polewali yang menjadi subjek dalam penelitian ini menunjukkan bahwa ada 3 subjek yang masuk pada kategori tinggi dan ada 3 subjek yang masuk pada kategori rendah.

Hasil diatas menunjukkan bahwa hasil tes pengetahuan pedagogic guru masih beragam. Berdasarkan hasil wawancara mengenai pemahaman terhadap tes pengetahuan pedagogic menunjukkan masih banyak guru yang menganggap bahwa tes semacam ini sulit walau bagus karena menantang dan ada juga yang menganggap bahwa tes semacam ini sudah sering didapatkan pada saat pelatihanpelatihan maupun pada saat UKG.

Sedangkan standar perolehan nilai untuk menentukan kategori yang dimaksud dapat dilihat pada tabel dibawah ini.

Tabel 1. Kategorisasi tingkat pengetahuan pedagogik guru

(Sumber : Permenneg PAN dan RB No. 16 Tahun 2009)

\begin{tabular}{|c|c|}
\hline Nilai (Persentase) & Kategori \\
\hline $76-100$ & Pengetahuan pedagogik tinggi \\
\hline$\leq 75$ & Pengetahuan pedagogik rendahh \\
\hline
\end{tabular}

Walaupun hasil perolehan nilai tes di atas menunjukkan bahwa pengetahuan pedagogik guru tidak ada yang mencapai kategori tinggi namun tetap dilakukan wawancara kepada responden untuk mengetahui sejauh mana pemahaman mengenai penerapan pendekatan scientific dalam pembelajaran matematika

Aktivitas guru SMP Negeri di Polewali Mandar

Tabel 2. Aktivitas guru SMP Negeri di Polewali Mandar dalam pembelajaran Matematika

\begin{tabular}{|c|l|c|c|c|c|c|c|}
\hline \multirow{2}{*}{ No } & \multicolumn{2}{|c|}{ Aspek yang diamati } & \multicolumn{6}{|c|}{ Responden } \\
\cline { 2 - 7 } & 1. & 2 & 3 & 4 & 5 & 6 \\
\hline 1. & $\begin{array}{l}\text { Kegiatan Pendahuluan: } \\
\text { a. Menyampaikan tujuan } \\
\begin{array}{l}\text { pembelajaran dengan } \\
\text { memberikan penjelasan } \\
\text { mengenai kerangka isi dari } \\
\text { materi yang diajarkan. }\end{array}\end{array}$ & 4 & 3 & 3 & 2 & 3 & 4 \\
$\begin{array}{l}\text { bemberikan apersepsi } \\
\text { materi yang diajarkan }\end{array}$ & 3 & 2 & 3 & 2 & 2 & 3 \\
\hline
\end{tabular}


PEPATUDZU: Media Pendidikan dan Sosial Kemasyarakatan p-ISSN: 2087-3476 | e-ISSN: 2541-5700

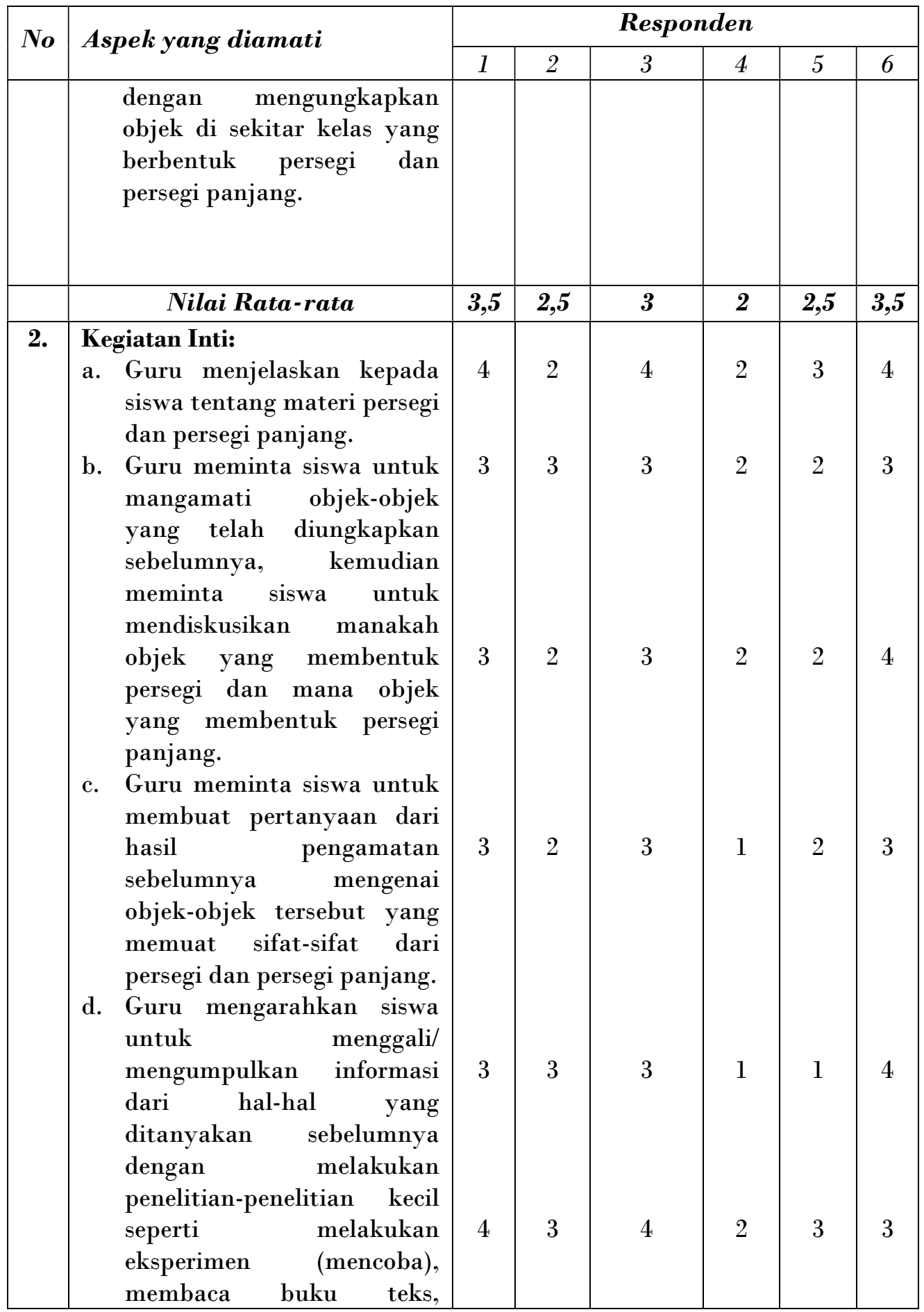


PEPATUDZU: Media Pendidikan dan Sosial Kemasyarakatan p-ISSN: 2087-3476 | e-ISSN: 2541-5700

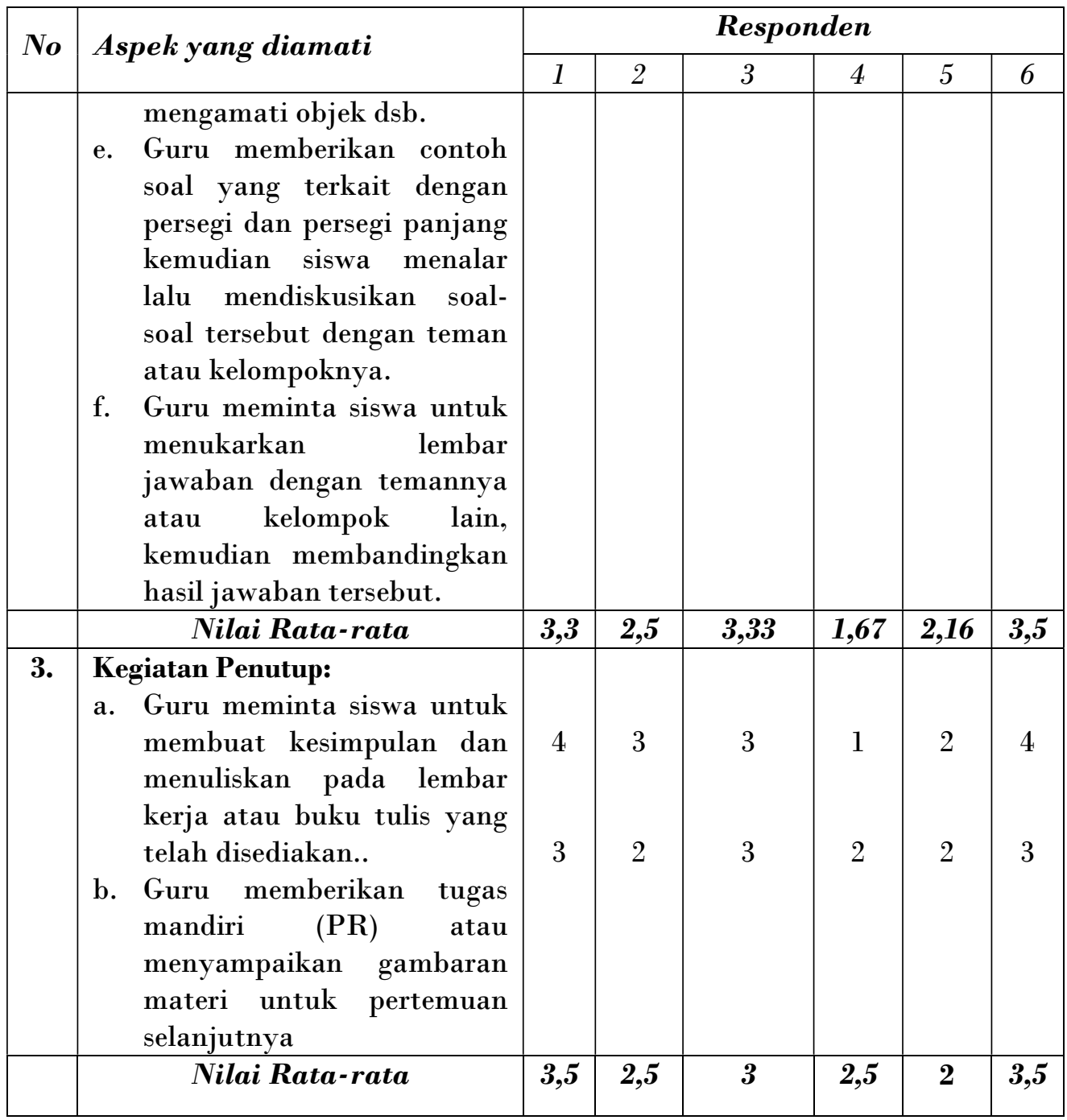

Kompetensi pedagogik guru matematika SMP Negeri di Polewali di kategorikan pengetahuan pedagogik tinggi dan pengetahuan pedagogik rendah. Dimana objek penelitian sebanyak enam orang guru matematika dari tiga sekolah yang berbeda (SMP Negeri 3 Polewali, SMP Negeri 2 Polewali, dan SMP Negeri 1 Polewali) di setiap sekolah mengambil dua guru matematika yang pengetahuan pedagogik tinggi dan pengetahuan pedagogik rendah.

Pengetahuan pedagogik guru Matematika dalam penelitian ini terbagi pengetahun pedagogik tinggi dan pengetahun pedagogik rendah, untuk guru Matematika yang berada dalam kategori pengetahun pedagogik tinggi pada 
umumnya guru matematika tersebut berdasarkan hasil wawancara pernah mengikuti pelatihan-pelatihan yang berkaitan dengan pembelajaran dengan menggunakan pendekatan scientific baik melalui pelatihan kurikulum 2013 maupun kegiatan yang dilaksanakan oleh sekolah yang bersifat internal. Sedangkan untuk guru Matematika yang berada dalam kategori pengetahuan pedagogik rendah pada umumnya guru matematika tersebut berdasarkan hasil wawancara belum pernah mengikuti pelatihan-pelatihan yang serupa namun hanya mendengar dan mengetahui mengenai pembelajaran pendekatan scientific melalui diskusi dengan teman sejawat atau hanya mendengar melalui media pada saat pencanangan kurikulum 2013.

\section{SIMPULAN}

Tingkat pengetahuan pedagogik guru yang memperoleh kategori rendah yaitu mencakup 1) menguasai karakteristik peserta didik, 2) menguasai teori belajar dan prinsip-prinsip pembelajaran yang mendidik, 3) mengembangkan kurikulum yang terkait dengan mata pelajaran yang diampunya, 4) menyelenggarakan pembelajaran yang mendidik, 5) memanfaatkan teknologi informasi dan komunikasi untuk kepentingan pembelajaran, 6) memfasilitasi pengembangan potensi peserta didik untuk mengaktualisasikan berbagai potensi yang dimiliki, 7) berkomunikasi secara efektif, empatik, dan santun dengan peserta didik, 8) menyelenggarakan penilaian dan evaluasi proses dan hasil belajar, 9) memanfaatkan hasil penilaian dan evaluasi untuk kepentingan pembelajaran, 10) Melakukan tindakan reflektif untuk peningkatan kualitas pembelajaran. Pada umumnya belum menunjukkan hasil yang baik karena tidak terbiasa menjawab tes semacam itu sehingga menjadi sebuah masalah.

\section{SARAN}

Berdasarkan kesimpulan pada penelitian ini, maka guru sebaiknya dalam pembelajaran menerapkan pendekatan scientifict agar guru memiliki mampu memahami karakteristik peserta didik, kemampuan merencanakan dan melaksanakan pembelajaran, kemampuan komunikasi dengan peserta didik, kemampuan melaksanakan evaluasi dan penilaian proses hasil belajar, serta pengembangan peserta didik untuk mengaktualisasikan berbagai potensi yang dimilikinya

\section{DAFTAR PUSTAKA}

Hosnan, M. 2014. Pendekatan Saintifik dan Kontekstual dalam Pembelajaran Abad 21. Bogor: Ghalia Indonesia.

Sadulloh, Uyoh dkk. 2011. Pedagogik (Ilmu Mendidik). Bandung: Alfabeta. 
Satori, Djam'an dan Aan Komariah. 2011. Metodologi Penelitian Kualitatif. Bandung: CV. Alfabeta

Sani, Ridwan Abdullah, 2014. Pembelajaran Saintifik untuk Implementasi Kurikulum 2013. Jakarta : Bumi Aksara

Sriyanti, Lilik. 2013. Psikologi Belajar. Yogyakarata: Ombak 